gifts that have made the Institute possible. Particularly notable have been the contributions of Spelman College, Emory University and Georgia State University.

\section{Janda Completes Latest APSR Index}

A new cumulative index to the American Political Science Review covering volumes 63 through 89 (1969-1995) has just been completed, and should be available to scholars and institutions this summer. Kenneth Janda and Richard Powell, Northwestern University, assisted by Kristin K. Stehouwer, have prepared the index. The project extends a project begun by Janda in 1964 (and last updated in 1969) to index the Review from its inception in 1906. The Association will publish a text version of the Index for sale to individuals and libraries, and will also post the index on its World Wide Web site.

The new volume references a total of 1370 items-articles, research notes, communications, and rejoinders. It uses a "key-work-incontext" (KWIC) technique to identify articles. Keywords are all substantive words in the title, plus some additional keywords added by Janda for titles that were not selfdescriptive. The index aligns keywords down the center of the page, with a portion of the article title on either side. Each title, on average, yields about 6 keywords, listed alphabetically in the context of the whole article title. There are also first author and co-author listings in the index.

As Janda notes in his preface to the new volume, the Association published its first cumulative index to the Review in 1917, and a second in 1926. No index was then published for 40 years, until Janda began experimenting in the early 1960 's with KWIC indexing and was invited by the Association to supervise an experimental project to apply nascent computer technology to indexing the Review. The resulting volume, published in 1964 , proudly displays sketches of actual punch cards used in the coding. The Association is indebted to
Kenneth Janda both for his initiative in the 1960's in developing and applying new indexing technology in the Review, and for following up the project now.

\section{Past Issues of $A P S R$ Available On-Line}

Beginning this fall, back issues of the American Political Science Review will be available electronically in fully searchable, digital form in libraries participating in the JSTOR electronic journal storage project. JSTOR is a non-profit initiative sponsored by the Mellon Foundation to create an electronic database containing major journals in the social sciences. APSA is one of the first associations to reach an agreement with JSTOR on an electronic database. Other journals accessible at the outset along with the APSR will be the American Economic Review and the American Historical Review.

This initiative to develop electronic access to the Review will develop in several phases. In the first phase, access to back issues will be available through college and university libraries subscribing to JSTOR. Back issues will be 3 years or more prior to the current issue, and will be updated annually. APSA is working with JSTOR now on plans for subsequent phases which will provide individual access to the database and bring current issues on-line.

Users accessing the Review through a library subscribing to JSTOR will access the journal onscreen through a World Wide Web connection, using Netscape or a compatible browser. The actual storage site is at the University of Michigan. The on-screen image will be a faithful image of the actual Journal page, scanned in a $600 \mathrm{dpi}$, and this can be printed, at the site's discretion, to produce a copy of the page clearer than most typical photocopy machines. A text database, created through optical character recognition applied to the scanned image, is also being created. This will be error-checked within titles and abstracts or first paragraphs. It will reside "behind the scenes," keyed to page images, to allow full-text searching of all articles, tables of contents, footnotes, and even advertisements.

An especially valuable feature of the electronic database will be searches that can stretch across all journals in the database, not just the APSR. Because this technology now truly integrates journal research materials within the social sciences, the JSTOR project is placing a high priority on getting a critical mass of key journals in major social science fields into the database. APSA will play an active role in helping answer questions other political science journal publishers have about whether to join the project.

The JSTOR concept was formulated by William G. Bowen, President of the Mellon Foundation, to help find a cost-effective way for scholarly publishers, college and university libraries, and faculty, students, and other scholars to benefit from new electronic technology. The project seeks to provide savings to libraries through reduced shelving and storage costs, and protections to publishers from subscription revenue losses. JSTOR has been established as a non-profit corporation. Bowen is Chairman of the Board, and other founding board members are Richard De Gennaro, Harvard College Library; Mary Patterson McPherson, President of Bryn Mawr College; Cathleen Morawetz, Professor of Mathematics, New York University and President of the American Mathematical Society, W. Taylor Reveley III, Partner, Hunton and Williams and Trustee of the Andrew W. Mellon Foundation; Gilbert Whitaker, retired Provost of the University of Michigan; and Elton White, former President of NCR and Trustee of Berea College.

APSA has negotiated an important downside protection agreement with JSTOR which will compensate the Association if this electronic database initiative results in lost institutional memberships in the Association. The Association's copyright for all of the published materials also remains unchanged. There are some other revenue risks for the Association, such as likely 